\title{
Hepatic portal vein gas associated with intestinal ischemia and acute gastric dilatation: a case report
}

\author{
Yun $\operatorname{Pan}^{\wedge}$ \\ Department of Emergency, Zhejiang University, School of Medicine, Sir Run Run Shaw Hospital, Hangzhou, China \\ Correspondence to: Yun Pan. Department of Emergency, Zhejiang University, School of Medicine, Sir Run Run Shaw Hospital, 3 Qingchun East Road, \\ Hangzhou 310016, China. Email: 21218182@zju.edu.cn.
}

\begin{abstract}
Hepatic portal vein gas (HPVG) is a rare and alarming radiographic finding for patients especially those who had intestinal ischemia. Some surgeons may learn it from books, literature and internet while they may not treat it in a real patient. It often indicates a very serious infection which could result in septic shock even death within a very short time, even though the mortality of patients with HPVG went down with the increased use of computed tomography and ultrasound which allows early and highly sensitive detection of such severe illnesses. Here I report a case in which an 84-year-old man was admitted to emergency department for three days of vomiting and two days of abdominal distension after eating an apple who had HPVG associated with intestinal ischemia and acute gastric dilatation and then died of septic shock in a short time. And the pathogenesis of HPVG is not completely clear at present, while three hypotheses may explain the relation between them. Attention must be paid closely to the patient who has HPVG associated with intestinal ischemia, and something must be done because it may indicate a life-threatening acute abdomen.
\end{abstract}

Koywords: Hepatic portal vein gas (HPVG); intestinal ischemia; acute gastric dilatation; case report

Submitted Sep 02, 2020. Accepted for publication Dec 08, 2020.

doi: 10.21037/apm-20-1764

View this article at: http://dx.doi.org/10.21037/apm-20-1764

\section{Introduction}

Hepatic portal vein gas (HPVG) is a rare phenomenon. Some surgeons may learn it from books, literature and internet while they may not treat it in a real patient. The diagnosis of HPVG is usually made by plain abdominal radiography, sonography, color Doppler flow imaging, or computed tomography. Computed tomography has higher sensitivity for the diagnosis of HPVG as compared to sonography and plain radiography (1). In the computed tomography, HPVG appears as linear or branching image in the tiny branch of portal vein because gas is transported to the liver edge along with the blood flow (2). It mainly presents in the liver parenchyma within 2 centimeters of the Glisson's capsule, especially in the case of left lobe $(3,4)$. Gas within the intrahepatic biliary channels often locates in the central liver parenchyma, which could help identification between them. The first HPVG was reported in 1955 by Wolfe and Evans (5). HPVG often appear with intestinal ischemia and necrosis, but also seen sometimes in other abdominal conditions such as gastric dilatation, gastric ulcer, ulcerative colitis, diverticulitis, pelvic abscess, necrotizing enterocolitis, intra-peritoneal tumor, Crohn's disease, cholangitis, pancreatitis and even after endoscopic procedures (6).

I present the following article in accordance with the CARE reporting checklist (available at http://dx.doi. org/10.21037/apm-20-1764).

\section{Case presentation}

An 84-year-old man was admitted to emergency department

\footnotetext{
^ ORCID: 0000-0002-6328-7382.
} 

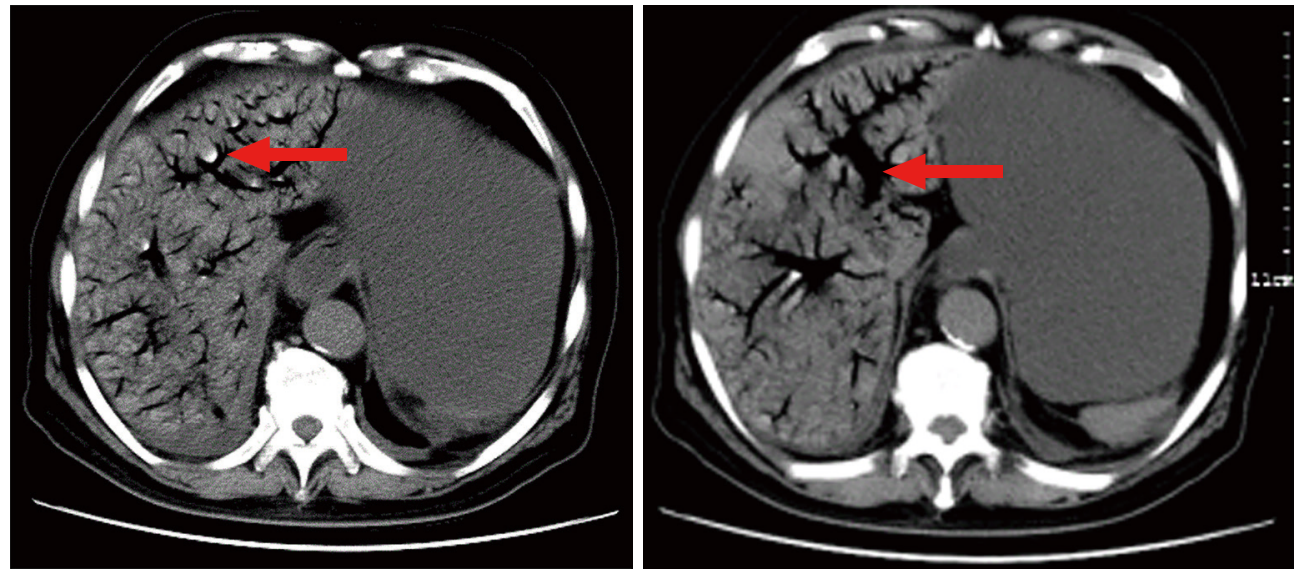

Figure 1 CT demonstrated massive gas in hepatic portal vein (arrows) and gastric dilatation.

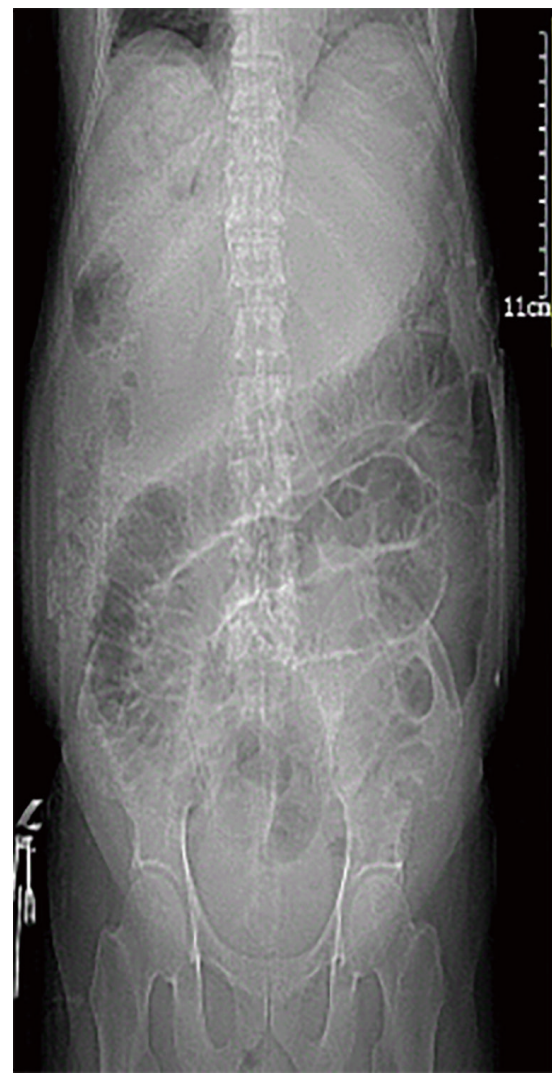

Figure $2 \mathrm{X}$ ray demonstrated ileus and gastric dilatation.

for three days of vomiting and two days of abdominal distension after eating an apple. Before the onset of the disease, the patient was in good health. His medical history included coronary heart disease, hypertension and type
2 diabetes. On admission, the patient's temperature was 36.7 degrees Celsius, heart rate was 120 beats per minute, respiratory rate was 18 beats per minute and blood pressure was 130/80 mmHg. Physical examination showed a grossly distended abdomen while abdomen was soft, no tenderness or rebound tenderness. Routine blood test showed a white blood cell count of 11,100 per cubic millimeter (reference range, 4,000 to 10,000 per cubic millimeter), a creactive protein of $170 \mathrm{mg}$ per liter (reference range, 0 to $5 \mathrm{mg}$ per liter). We further performed routine CT examination and $\mathrm{X}$ ray on the patient. And CT scanning and $\mathrm{X}$ ray showed massive HPVG and small bowel obstruction and gastric dilatation (Figures 1,2). A nasogastric tube was intubated immediately to decompress. Then a contrast-enhanced computed tomography was arranged to see if the patient had intestinal ischemic necrosis. And the contrast-enhanced CT indeed showed intestinal ischemia but no necrosis (Figure 3). Then the patient was hospitalized, treated with intravenous antibiotics, and intubated an ileus tube via $\mathrm{X}$-ray guided interventional therapy. However, the patient had a septic shock and cardiac arrest several hours later, and he was given cardiopulmonary resuscitation immediately and then transferred to intensive care unit for further treatment. Unfortunately, his condition deteriorated rapidly, progressing to organ dysfunction and failure and died three days after admission.

All procedures performed in studies involving human participants were in accordance with the ethical standards of the institutional research committee and with the Helsinki Declaration (as revised in 2013). Written informed consent was obtained from the patient's daughter. 

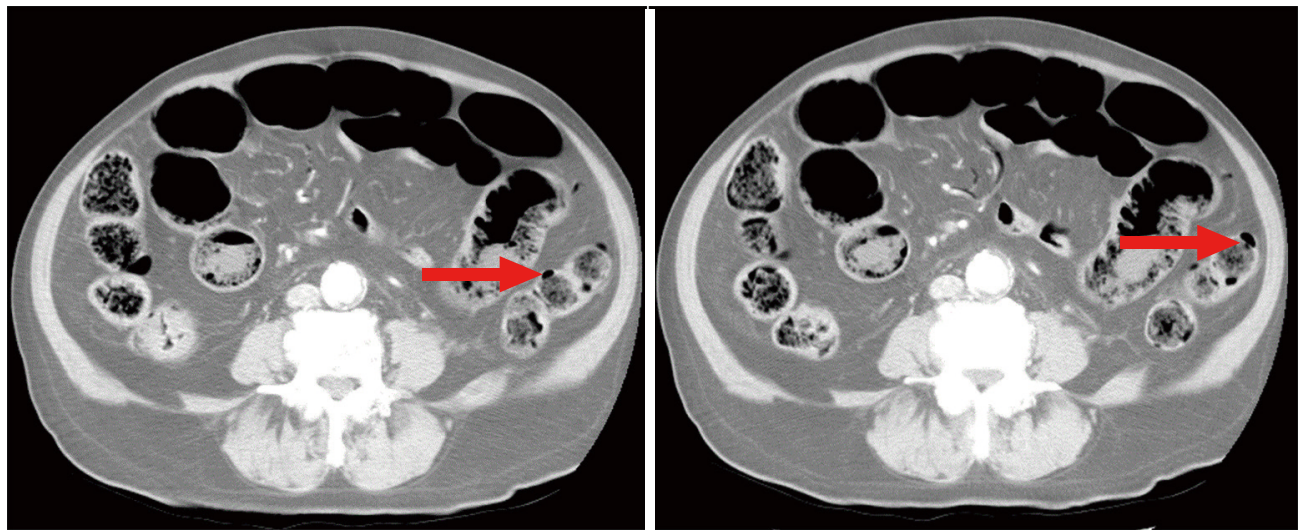

Figure 3 CT demonstrated intestinal ischemia (arrows).

\section{Discussion}

HPVG is an alarming radiographic finding for surgeons. It often indicates a very serious infection which could result in septic shock within a very short time. Early studies have shown that the mortality of HPVG is up to an alarming mortality rate of $75 \%$ (5), while a literature survey in 2001 found a total mortality of only $39 \%$ explained by an increased detection of benign cases with the increased use of CT scan and ultrasound in the patient (7). However the patient died in this case and it was just six days from initial symptoms to death, three days from discovery of HPVG to death, even the patient was diagnosed with little delay and had been treated on admission.

The pathogenesis of HPVG is not completely clear at present, while three hypotheses may explain the relation between them. Firstly, bacteria in portal vein system generate gas when suffering from microbial infection, especially gas-producing bacteria infection. Secondly, the intestinal mucosa is damaged and then gas escapes to the submucosa and blood vessels through the damaged intestinal mucosa, and then enters the portal vein system. Thirdly, the mixed type (8).

\section{Conclusions}

HPVG is a rare and alarming radiographic finding. And attention must be paid closely to the patient who has HPVG associated with intestinal ischemia. Once seeing this phenomenon, something must be done because it often indicates a life-threatening acute abdomen.

\section{Acknowledgments}

The author thanks Meghan for some language corrections. Funding: None.

\section{Footnote}

Reporting Checklist: The author has completed the CARE reporting checklist. Available at http://dx.doi.org/10.21037/ apm-20-1764

Conflicts of Interest: The author has completed the ICMJE uniform disclosure form (available at http://dx.doi. org/10.21037/apm-20-1764). The author has no conflicts of interest to declare.

Ethical Statement: The author is accountable for all aspects of the work in ensuring that questions related to the accuracy or integrity of any part of the work are appropriately investigated and resolved. All procedures performed in studies involving human participants were in accordance with the ethical standards of the institutional research committee and with the Helsinki Declaration (as revised in 2013). Written informed consent was obtained from the patient's daughter.

Open Access Statement: This is an Open Access article distributed in accordance with the Creative Commons Attribution-NonCommercial-NoDerivs 4.0 International License (CC BY-NC-ND 4.0), which permits the noncommercial replication and distribution of the article with 
the strict proviso that no changes or edits are made and the original work is properly cited (including links to both the formal publication through the relevant DOI and the license). See: https://creativecommons.org/licenses/by-nc-nd/4.0/.

\section{References}

1. Schulze CG, Blum U, Haag K. Hepatic Portal Venous Gas. Imaging Modalities and Clinical Significance. Acta Radiol 1995;36:377-80.

2. Susman N, Senturia HR. Gas Embolization of the Portal Venous System. Am J Roentgenol Radium Ther Nucl Med 1960;83:847-50.

3. Abboud B, El Hachem J, Yazbeck T, et al. Hepatic Portal Venous Gas: Physiopathology, Etiology, Prognosis and Treatment. World J Gastroenterol 2009;15:3585-90.

4. Sebastià C, Quiroga S, Espin E, et al. Portomesenteric

Cite this article as: Pan Y. Hepatic portal vein gas associated with intestinal ischemia and acute gastric dilatation: a case report. Ann Palliat Med 2021;10(6):7095-7098. doi: 10.21037/ apm-20-1764
Vein Gas: Pathologic Mechanisms, Ct Findings, and Prognosis. Radiographics 2000;20:1213-24; discussion 1224-6.

5. Wolfe JN, Evans WA. Gas in the portal veins of the liver in infants; a roentgenographic demonstration with postmortem anatomical correlation. Am J Roentgenol Radium Ther Nucl Med 1955;74:486-8.

6. Kinoshita H, Shinozaki M, Tanimura H, et al. Clinical features and management of hepatic portal venous gas: four case reports and cumulative review of the literature. Arch Surg 2001;136:1410-4.

7. Nelson AL, Millington TM, Sahani D, et al. Hepatic portal venous gas: the ABCs of management. Arch Surg 2009;144:575-81.

8. Liebman PR, Patten MT, Manny J, et al. Hepatic--portal venous gas in adults: etiology, pathophysiology and clinical significance. Ann Surg 1978;187:281-7. 